\title{
A EPOPEIA NA CONTEMPORANEIDADE: O “IMPÉRIO" DE BLOOM, EM UMA VIAGEM À ÍNDIA, DE GONÇALO M. TAVARES ${ }^{1}$
}

\author{
Isabele Corrêa Vasconcelos Pereira (URI) \\ Silvia Helena Niederauer (URI) \\ Ilse Maria da Rosa Vivian (URI)
}

Resumo: Com o intuito de identificar e discutir os elementos que permitem reconhecer, a partir de Uma Viagem à Índia: melancolia contemporânea (um itinerário) (2010), de Gonçalo M. Tavares, a dimensão da épica contemporânea, pretende-se analisar, com base em caráter bibliográfico e comparatista, o texto literário Uma Viagem à Índia (2010) e discutir de que maneira ele sistematiza as características da epopeia clássica. Logo, a narrativa do lusófono Gonçalo M. Tavares pode vir a ser um exemplo da nova formação literária no que tange ao gênero épico, por sua percepção hodierna sobre a realidade e sua capacidade de gerar hibridismos e intertextos relevantes para a literatura.

Palavras-chave: Literatura Comparada; Gênero Épico; Contemporaneidade.

Resumen: Con el objetivo de identificar y discutir los elementos que permiten reconocer, a partir de Un Viaje a la India: melancolía contemporánea (un itinerario) (2010), de Gonçalo M. Tavares, la dimensión de la épica contemporánea, pretendiese analizar, con base en carácter bibliográfico y comparatista, el texto literario Un Viaje a la India (2010) y discutir de qué forma él sistematiza las características de la epopeya clásica. Luego, la narrativa del portugués Gonçalo M. Tavares puede ser un ejemplo de la nueva formación literaria con respecto al género épico, por su percepción moderna sobre la realidad y su capacidad de engendrar hibridismos e intertextos relevantes para la literatura.

Palabras-clave: Literatura Comparada; Género Épico; Contemporaneidade.

1 Recorte da Dissertação de Mestrado apresentado ao Programa de Pós-graduação em Letras - Mestrado em Letras, área de concentração em Literatura Comparada da Universidade Regional Integrada do Alto Uruguai e das Missões (URI), Campus de Frederico Westphalen no ano de 2015. 


\section{INTRODUÇÃO}

O estudo e análise apresentados subsequentemente se inserem nas relações entre Literatura, História e Memória, pois recuperam, via texto literário, as relações entre a literatura e a história entendendo os discursos como construções socioculturais, entre realidade e ficcionalidade. Sendo assim, compreende-se o espaço desses discursos como lugar de identidade na subjetividade humana, capaz de estreitar os diálogos que compõem o campo da representatividade estética.

A partir desta temática, o trabalho pretende desenvolver, sob o viés conceitual da tradição dos gêneros literários e sua transformação, uma análise de objeto literário, comparando os discursos, observando os elementos de aproximação e afastamento, quanto à proposta ficcional e à problemática da contemporaneidade.

Para tanto, a metodologia utilizada apresenta caráter bibliográfico e será realizada a partir do estudo e sistematização de pressupostos acerca do tema escolhido, no presente caso, o ponto referencial será a obra do escritor português Gonçalo M. Tavares, Uma Viagem à Índia: melancolia contemporânea (um itinerário) (2010).

Para delinear esse estudo, busca-se descrever, refletir e discutir, com base no corpus, as implicações entre homem e 
realidade e suas representações no gênero épico. Traçando, desta forma, um perfil comparatista como metodologia, destaca-se as marcas que se referem à construção do texto, aos valores transmitidos pelas expressões artísticas, elementos da tradiçãoliterária como mímesis, verossimilhança e articulações típicas de um discurso contemporâneo.

Assim posto, na literatura, como nas demais áreas artísticas, houve um crescente desenvolvimento em termos estéticos no decorrer da história e das transformações sociais desde as grandes narrativas épicas até a contemporaneidade. Os estilos literários, por exemplo, variaram em forma e conteúdo de acordo com os valores estéticos de cada nova geração. Dependeram ainda das tradições e particularidades das sociedades a que pertenciam. Nesse contexto, lan Watt (2010) aponta o século XVIII como o momento em que ocorre a passagem do pensamento coletivo, retratado nos épicos, para a experiência individual, assim oferecendo suporte para a transformação das narrativas que culminariam no romance moderno.

Partindo do objeto literário Uma Viagem à Índia: melancolia contemporânea (um itinerário) (2010), de Gonçalo M. Tavares, pretende-se delinear a análise sobre a obra em questão, a observar de que maneira o texto estabelece 
vínculo com o gênero épico na contemporaneidade. A partir disso, ambiciona-se investigar os processos transformacionais existentes entre o gênero épico e o texto mencionado, tomando por base alguns aspectos da epopeia clássica, como a mímesis, o ambiente atrelado aos fatores sociais, a estrutura narrativa e o sujeito como personagem ficcional.

Exposto isso, tem-se como propósito fundamental identificar e discutir os elementos que permitem reconhecer, a partir de Uma Viagem à Índia², de Gonçalo M. Tavares (2010), a dimensão da épica contemporânea.

Partindo da importância da arte estética definida por Nelly Novais Coelho (1986) como manifestação para o reconhecimento de mundo enquanto elemento vital da essência humana entre a realidade comum e o indizível, a perspectiva artística une-se à formação literária para dar voz à percepção.

Considerando a formação literária, há que localizá-la quanto aos novos tempos, valores, comportamentos sociais e estéticos que geram novas manifestações artístico-literárias. O texto Uma Viagem à Índia, de Gonçalo M. Tavares (2010), constitui-se como um exemplo dessa nova formação literária 2 TAVARES, Gonçalo M. Uma Viagem à Índia: melancolia contemporânea (um itinerário). São Paulo: Leya, 2010. A partir de agora, designar-se-á apenas parte do título: Uma Viagem à Índia, a data de publicação e as respectivas páginas. 
no que tange ao gênero épico, por sua percepção hodierna sobre a realidade e sua capacidade de gerar hibridismos e intertextos relevantes para a literatura.

\section{VIAGEM À ÍNDIA: A MÍMESIS CONTEMPORÂNEA}

Distante temporalmente de Platão e Aristóteles, que propuseram as primeiras teorias sobre a mímesis, Lukács (2000), já na contemporaneidade, expressa que a mímesis tem uma estreita relação com o conhecimento, com o social e com os fatores históricos que a condicionam: "a vida faz-se criação literária, mas com isso o homem torna-se ao mesmo tempo o escritor de sua própria vida e o observador dessa vida como uma obra de arte criada. Essa dualidade só pode ser configurada liricamente" (p.124). Nas palavras de Rejane Oliveira (2003, p.182):

É nesse ponto que a referência a Lukács torna-se indispensável, por ver na mimese um fato elementar da vida humana, tomando parte do desenvolvimento da humanidade, estritamente relacionado às condições objetivas da existência. $\mathrm{O}$ homem e o seu destino são o centro do reflexo estético, de modo que a literatura torna-se essencial para a elevação do indivíduo e do seu ser social.

Oliveira (2003) refere-se ao complexo e denso debate sobre a mímesis. A reprodução por si só deve obedecer a sua 
gênese primitiva, retratar o real. Essa reprodução estética, para Lukács (2000), deve inscrever o processo histórico e o processo de evolução da humanidade:

Nessa possibilidade, sem dúvida, reside a problemática decisiva dessa forma romanesca: a perda do simbolismo épico, a dissolução da forma numa sucessão nebulosa e não configurada de estados de ânimo e reflexões sobre estados de ânimo, a substituição da fábula configurada sensivelmente pela análise psicológica. (p.118)

O teórico observa que a arte reflete a vida e vice-versa. Nesse sentido, a arte expressa não só valores humanos, mas também os fenômenos relacionados à experiência humana: "Imitar é, para Lukács, uma atividade de domínio e conhecimento da realidade, um impulso orientado por finalidades práticas, segundo necessidades e contingências objetivas" (OLIVEIRA, 2003, p.184). Desse modo, fica claro que a mímesis, para Lukács, obedece a critérios de aprendizagem. Imita-se para se aprender as atividades e acontecimentos do mundo real. Ele se aproxima do conceito aristotélico, uma vez que ambos pregam que o conhecimento advém da observação e da reflexão da realidade.

W. Benjamin (1994) refere-se aí à mímesis, característica marcante nas teorias platônicas e aristotélicas no que tange à 
arte. O valor da representação na Antiguidade era outro: "Os gregos clássicos pensam sempre a arte como uma figuração enraizada na mímesis, na representação, ou, melhor, na 'apresentação' da beleza do mundo" (Apud GAGNEBIN, 1993, p.68). Não era permitido aos artistas criarem além do caráter real que uma obra espelhava, a nova obra deveria ser fiel ao evento retratado. A mímesis funcionava como o reflexo do mundo concreto.

Platão resiste à imitação, visto que, para ele, ela não é o real, apenas o reproduz. E, em meio a essa reprodução, se perderia o caráter de veracidade do objeto representado. As manifestações clássicas visavam à aproximação exacerbada com o real, uma imagem nítida do mundo que os cercava.

Contudo, esse conceito de mímesis abre algumas brechas para que se interponha sobre a arte a característica da semelhança. Quer dizer, aquela aproximação fidedigna com o real não é plenamente imutável, ela pode preceder alterações típicas da criação humana. "Como Aristóteles na Poética (1952), Benjamin distingue dois momentos principais da atividade mimética especificamente humana: não apenas reconhecer, mas também produzir semelhanças" (GAGNEBIN, 1993, p.80).

De um lado a representação da realidade e de outro a possibilidade de criar sob a imitação. Chega-se a um 
paradoxo em que a originalidade prevalece. Cada período histórico teve a sua leitura e produção dos objetos artísticos e é desta forma que prevalece a atenção sobre o critério de autenticidade. Até que com técnicas como a xilogravura e a litografia as obras conseguiam ser reproduzidas em maior escala. A era da técnica influenciou a reprodução em massa. Mesmo representando a vida cotidiana, as imagens artísticas não eram mais construídas pelas mãos humanas, eram carimbadas, copiadas e transpostas para que os olhos as lessem assim como se procedia com as atividades da imprensa.

Em Uma Viagem à Índia: melancolia contemporânea (um itinerário) (2010), do autor português Gonçalo M. Tavares, aparece não apenas a mímesis do ambiente contemporâneo em si, mas a retomada de outras narrativas no enredo a ponto de seguir os passos da epopeia clássica para representar a fragmentação da atualidade:

Esta repetição da viagem iniciática do Ocidente, tendo como "modelo" a dos Lusíadas, é uma original revisitação da mitologia cultural e literária do mesmo Ocidente, não como exercício sofisticado de des-construção (que também é) mas como versão lúdica e paródica de um quête, aleatória e como tal assumida. Não sei se existe entre nós - e mesmo algures - um objeto ficcional tão intrinsicamente 
"literário", quer dizer, o de uma "viagem" que é, em múltiplos sentidos, o da construção do barco literário da mesma viagem. (LOURENÇO, Apud TAVARES, 2010, p.9)

Para Eduardo Lourenço (Apud TAVARES, 2010, p.9), essa ficção "navega e vive entre os ecos de mil textos-objectos do nosso imaginário de leitores". O mesmo autor menciona a "dupla viagem" que é realizada ao adentrar na narrativa portuguesa contemporânea em virtude da multiplicidade de textos que a interceptam. A leitura e decifração do código proposto por Tavares (2010) causa uma sensação intratextual de retornar a outros textos dentro de um mesmo texto, gerando um tecido de objetos literários que se interpenetram em um diálogo inerente ao leitor.

Partindo disso, Bloom, protagonista de Uma Viagem à Índia: melancolia contemporânea (um itinerário), de Gonçalo Tavares (2010), é o retrato do sujeito contemporâneo proposto por Agamben (2013), que projeta-se para além do seu tempo nas relações com os novos dispositivos e com os amigos que encontra pelo caminho, exemplificando os espectros da realidade.

Bloom traz em seu âmago a melancolia típica da ausência de sentido do mundo. É um homem que decide partir de Lisboa em busca de algo, que não sabe bem o que é. Diz 
buscar uma mulher ou a sabedoria e caso encontre ambas juntas achará o que procura: "Procuro uma mulher, disse Bloom, ou então a sabedoria. Se em Paris não as encontrares juntas, responderam-lhe, pelo menos com uma delas te cruzarás. E uma pode levar-te à outra" (TAVARES, 2010, p.9596). Contudo, em virtude de um passado familiar trágico, ele busca em realidade, o esquecimento.

A viagem de Bloom se desdobra diante das suas vontades frente às interpelações do meio. A narrativa se constrói em imagem semelhante à realidade do século XXI: um sujeito sem perspectiva de futuro, em virtude de sofrimento amoroso, mediante uma sucessão de crimes passionais. Em razão desses acontecimentos, Bloom, a fim de esquecer o passado e almejar com ganas a sabedoria indiana, começa as suas aventuras no mapa europeu.

A viagem à Índia revela uma transposição do real para a ficção. Gonçalo M. Tavares (2010) conseguiu unir na narrativa aspectos fundamentais para aproximá-la do contexto do século XXI, um sujeito melancólico, perdido quanto a sua identidade e ao seu tempo, uma estrutura fragmentada em dez cantos, com um enredo híbrido que recupera grandes clássicos literários - Os Lusíadas, de Camões, e Ulisses, de James Joyce - a ponto de caracterizar a sua produção 
como uma anti-epopeia. O itinerário dessa melancolia contemporânea arma uma paródia do clássico em ambiente ficcional e estruturas modernas, algo que recupera a discussão de parecença com o real via artifícios de releitura moderna.

\section{ITINERÁRIO DA NARRATIVA: NOVOS DISPOSITIVOS}

O itinerário da narrativa Uma viagem à Índia (2010) traz imbricado em sua configuração um personagem em deslocamento espacial, temporal e identitário. Em meio a essa multiplicidade de deslocamentos, esse personagem, Bloom, o protagonista da história, edifica-se em diferentes dispositivos contemporâneos:

O dispositivo de Uma viagem à Índia é o de um poema provocantemente épico e antiépico. A sua realidade é a de um romance não menos provocantemente inscrito nos "cantos" e "estâncias", ao mesmo tempo prosaicas e hiper-literárias pelos ecos de todas as peripécias que lhe são como mar inacessível à plácida superfície do seu poema, total e totalizante. A sua "viagem" não desconhece todas as viagens já feitas. Sabe-se outra, como a de Camões se desejou. É entre tudo e nada, ao mesmo tempo trivial e sublime, mas hiper-consciente do seu caráter desesperado, da sua necessidade, da sua in-transcendência transcendente. (LOURENÇO, Apud TAVARES, 2010, p.13) 
A realidade da história de Bloom começa em Londres. Lá ele buscava o insólito e ao andarilhar sob as ruas londrinas se depara com três homens. Os homens e Bloom desentendemse. O protagonista sai, de certa forma, vitorioso após confronto físico com os homens, contudo, eles Ihe planejam uma vingança.

A vingança não dá certo, pois Bloom segue seus instintos e foge do ambiente em que preparavam-lhe uma armadilha. Ele decide, então, ir à Paris. Logo que chega à capital da França faz amizade com Jean M. O novo amigo divide com Bloom o guarda-chuva no dia chuvoso em que se conhecem e o acolhe na cidade. É ele também que o incita a contar a sua triste e melancólica trajetória:

O parisiense, voltemos a ele, queria que Bloom abrisse a torneira onde corre água cujo barulho conta histórias.

Que fizeste à tua vida, caro Bloom, para agora estares em plena viagem à Índia?

Onde e como falhaste? De que forma acertaste no alvo? (TAVARES, 2010, p.115)

Neste momento, há um deslocamento de tempo para o passado de Bloom, que narra todos os acontecimentos que o levaram a querer realizar uma viagem à Índia. Após contar a sua história, Bloom e Jean M. divertem-se em Paris. Desta cidade, o protagonista segue viagem rumo à Índia. 
Na Índia, conhece Anish, amigo recomendado por Jean M. para auxiliar Bloom a conhecer a cultura e os costumes indianos. Anish leva Bloom ao encontro com Shankra, o grande mestre que the ensinaria, então, sobre todas as coisas do mundo a ponto de torná-lo um sábio. Contudo, em meio a trocas dialógicas com Shankra, os conselheiros dele, tomados pela desconfiança, persuadem o pensamento do mestre para que tome os livros raros que levava Bloom em sua pequena maleta. Bloom, herói astuto, consegue se livrar de Shankra e sai da Índia junto com Anish.

Ambos retornam à Paris, onde o seu amigo Jean M. Ihes espera com três mulheres, um banquete e uma casa distante da cidade. Em plena crise de identidade e mergulhado num sentimento de perda e decepção, algo toma conta de Bloom e o leva a cometer um crime e retornar em fuga à Lisboa, o lugar de onde partira.

É com esse enredo que se delineia a narrativa de Uma Viagem à Índia (2010). Esse texto é modelar dos novos parâmetros estéticos, uma vez que lança sobre essa história diferentes elementos que se interpõem e carregam a personalidade da narrativa rumo ao contemporâneo. Gonçalo M. Tavares, portanto, consegue construir o itinerário de Bloom mesclando um pouco de romance, um pouco de epopeia, expressando todos os sentimentos conflitantes da atualidade. 
A estrutura recupera traços marcantes da epopeia clássica. O deslocamento de um personagem até a Índia em formato in media res, partindo da plena ação de conflito e preparação de vingança, para depois, quando em Paris, expor o passado que levou o protagonista a chegar até aquele momento:

E basta - disse Bloom.

Começarás a perceber agora por que razão estou em viagem

e o que procuro:

procuro uma mulher porque quero esquecer outra.

Eu amava uma mulher chamada Mary - disse Bloom ao parisiense Jean M e o meu próprio pai mandou matá-la. Eis a minha história. Síntese, síntese. E eis tudo. (TAVARES, 2010, p.155)

Após contar a sua triste história ao amigo francês, em tom de recuperação do passado para explicar as ações do presente e a vontade pela Índia, pela sabedoria e pelo esquecimento, retorna-se ao momento presente da narrativa e a história prossegue. Esse recurso é típico das epopeias clássicas e é retomado com vistas a recuperar um comportamento clássico mediante estéticas fragmentadas.

Outra característica de epopeia observada através da figura de Bloom é a divisão quase próxima da ordem proposição, invocação, dedicatória, narração e epílogo. Ocorre a manutenção da proposição em tom de apresentação 
da matéria ou de quem se cantará. As partes de invocação e dedicatória não fazem parte dessa nova composição épica. Contudo, a narração ao longo do Canto I ao Canto $X$ permanece, juntamente com o epílogo ao final do Canto X.

Algo que também mantém-se de acordo com o poema épico é o relato ficcional atrelado a cantos, precisamente dez cantos. Cada um desses cantos possui, aproximadamente, em torno de cem estrofes, sendo o último - o Canto $X$ - aquele que possui mais estrofes -156 estrofes.

Fora esses aspectos estruturais, outros que recuperam traços do clássico é a existência de um herói que, querendo ou não, representa um modelo de sujeito contemporâneo. $A$ presença desse personagem é fundamental para articular as engrenagens da obra entre história, estrutura e ambiente real.

À medida que se percebe a presença marcante da epopeia clássica, também se percebe a existência de elementos do romance. A narrativa não é mais em versos, mas sim em prosa. Há muita descrição de espaços, sentimentos e aventuras, além da presença marcante da diversidade de narradores entre os cantos, ora é uma voz em 3ạ pessoa, ora é a narração pela voz de Bloom, ora a narração ocorre pela voz de Jean M. Há a interposição e o diálogo do narrador com o leitor em certos momentos, e isso reforça a estética típica do século XXI. 
A viagem de Bloom faz parte de uma história de descobrimento do seu próprio interior, comportamento característico do homem contemporâneo. De acordo com Agamben (2013, p.71): “O contemporâneo coloca em ação uma relação especial entre os tempos".

A relação entre os tempos, proposta por Agamben (2013), pode ser observada na própria estrutura, ora com traços de epopeia, ora de romance. A narrativa portuguesa se estabelece como um texto híbrido:

Nietzsche situa a sua exigência de "atualidade", sua "contemporaneidade" em relação ao presente, numa desconexão e numa dissociação. Pertence verdadeiramente contemporâneo, aquele que não coincide perfeitamente com este, nem está adequado às suas pretensões e é, portanto, nesse sentido, inatual; mas, exatamente por isso, exatamente através desse deslocamento e desse anacronismo, ele é capaz, mais do que os outros, de perceber e aprender o seu tempo. (AGAMBEN, 2013, p.58)

O texto híbrido é a união entre as duas estéticas, tanto a romanesca, quando a epopeica. A hibridez é um atributo das novas demandas contemporâneas, visto que, ao que parece, não se tem muitos caminhos criativos a transitar. A constante inovação, em que o novo substitui o velho em um curto espaço de tempo, leva a invenção a um estado de superação 
que nem sempre é possível. Os produtos se reinventam, as estéticas se remodelam, unem estruturas e contextos num mesmo ambiente.

Assim, o objeto de análise é um exemplo de híbrido contemporâneo a partir dos intertextos que estabelece com outras narrativas - Os Lusíadas e Ulisses. O exercício da re-leitura e/ou re-escrita é um re-encontrar-se com interpretações do primeiro texto em contato com um mundo novo.

\section{BLOOM, O SUJEITO MELANCÓLICO}

Bloom é o protagonista de Uma Viagem à Índia: melancolia contemporânea (um itinerário) (2010). Ele se apresenta como um sujeito melancólico ao longo de toda a trama em virtude da sua relação com o tempo, o seu deslocamento pelo espaço, a sua relação com os demais personagens e com as mais variadas estruturas sociais.

Bloom parte rumo à Índia em busca de sabedoria e de esquecimento, pois viveu um grande trauma envolvendo o seu amor por Mary. Em verdade, ele quer redimir-se dos erros que recorda ao longo da narrativa, evocando momentos da relação com o pai e da relação com Mary.

Localizado primeiramente em Londres, Bloom não fica satisfeito com a sua ida até a capital londrina porque lá vive 
conflitos físicos e articulações de vingança por parte de seus inimigos. Primeiro ele observa. Na primeira etapa da viagem, encontra-se sem dinheiro e sem conhecer pessoas que possam lhe ajudar. Então, procura amigos.

Agamben (2013, p.89) define a amizade como a instância do com-sentimento da existência do amigo com a sua própria. Isso exige um estatuto tanto ontológico, quanto político. A amizade é, portanto, uma com-divisão, é "um outro si mesmo" (p.87). E, na verdade, é isso que procura Bloom, encontrar-se na figura do outro, sob a produção de certo espelhamento humano.

Bloom busca por amigos nas cidades em que visita, e os únicos com quem consegue tecer laços da amizade são Jean M., de Paris, e Anish, da Índia. Os demais se aproveitam de sua situação de exposição extrema enquanto estrangeiro e Ihe armam emboscadas. Com apenas poucos amigos, sem deparar-se com alguns "outros si" (AGAMBEN, 2013, p.87), se estabelece cada vez mais o sentimento de melancolia.

Bloom reflete sobre a relação com o outro no grande e melancólico tempo em que vive: "As vidas dos outros não nos comovem, pensa Bloom" (TAVARES, 2010, p.44). Isso ratifica o pensamento individualista da contemporaneidade e expõe como se dão as relações de amizade envolvendo os 
sentimentos; sobre isso, Bloom afirma que é difícil resolver os problemas daqueles que não nos dizem respeito.

O sentimento de amizade, sobre o qual se reportava Bloom, é referido por Agamben (2013, p.90) ao afirmar que o amor é a confirmação de uma alteridade imanente na "mesmidade", isto é, manter um sentimento pelo outro com base em si mesmo. Assim sendo, essa relação é transposta por um "com-sentir" que se desloca do eu para o outro, o amigo, o outro do mesmo. O teórico resume a amizade como a "sensação mais íntima de si".

Em função disso, e já tendo alguma experiência sobre o egoísmo e egocentrismo hodierno, Bloom desconfiou que algo não ia bem. Os homens que o acolheram em Londres queriam, na verdade, roubar-lhe a mala e os bens que carregava dentro dela. Percebendo o que poderia acontecer, Bloom pressentia um ataque violento por parte dos três homens e do pai deles. Quando a disputa de fato começou, o protagonista preparou socos com os punhos cerrados que em cheio atingiram os covardes homens. Desnorteados, saíram correndo e ganharam dianteira frente ao pai que ficou para trás e acabou levando uma pedrada destinada a Bloom pela incompetência da pontaria de seu filho.

Quando já recuperados da correria da fuga, os homens covardes começaram a preparar vingança. Bloom distraia- 
se com facilidade dos acontecimentos que o cercavam e se isolava em devaneios típicos do sujeito contemporâneo. Nesses momentos, a narrativa sequencial se irrompe de reflexões e inquietudes. Bloom observa a janela, movia o pensamento em direção ao passado, onde agora transitavam carros, em menos de dois séculos circulavam cascos de cavalos e exércitos de guerra. Pensa em como a vida é agora cheia de máquinas e marcas de indústrias.

Essas inquietudes que levam o sujeito contemporâneo a uma crise temporal recobrem as dobradiças da narrativa sob as reflexões de Bloom. Ele traduz perfeitamente o sentimento de não-pertencimento do mundo moderno. Através disso, Tavares (2010, p.55) delineia a personalidade de Bloom: "Bloom era, enfim, mau desenhador do presente mas extraordinário a reproduzir o que ainda não existe: o futuro".

Isso caracteriza o que Agamben (2013, p.59) articula sobre o sujeito contemporâneo projetar-se sempre para outros tempos que não o presente. Para ele, a contemporaneidade é a relação com o próprio tempo, que adere uma dissociação e um anacronismo. Bloom é um representante dessa agonia de deslocamento temporal para aonde não se vive, apenas se projeta a vida na iminência do desgaste sob 
o clima de renovação: "Diga-se que a matéria-prima de um acontecimento intenso e excitante é, apesar de tudo, desgastável. O material dos factos (se olharmos atentamente) é nada" (TAVARES, 2010, p. 59).

\section{CONSIDERAÇÕES FINAIS}

Ao vislumbrar a adaptação artística, cria-se um universo autônomo em ambiente ficcional. Os personagens nascem das palavras e renascem na configuração imaginária de cada leitor/ouvinte de uma história. Constituem-se grandes representantes humanos, ainda que não passem de entidades imaginárias. A expressão literária apresenta diferentes formatos de acordo com as demandas e traduz em seu âmago algo do corpo social que a circunda:

Para nossa época, Arte é linguagem, ou seja, toda a expressão artística é vista como um fenômeno expressivo, como uma linguagem específica: uma forma peculiar que busca expressar uma vivência ou uma experiência humana, em termos de harmonia ou de impacto [...]. (COELHO, 1986, p.29 - grifo do autor)

Sendo assim, a considerar a análise sobre o texto Uma Viagem à Índia: melancolia contemporânea (um itinerário) (2010), de Gonçalo M. Tavares, pode-se perceber esse retrato do contemporâneo na estética literária representada 
pela narrativa de Bloom e o seu deslocamento em busca de autoconhecimento, esquecimento e sabedoria.

O "Império de Bloom" identifica o descortinamento do sujeito que decidiu viajar em fuga de seu passado trágico a fim de esquecê-lo e adquirir sabedoria. O protagonista parte de Lisboa rumo à Índia. Ao longo deste itinerário, ele tece reflexões sobre o seu modo de estar no mundo, sobre a civilização contemporânea, sobre a natureza e a relação desta com o ser humano, sobre a sua genealogia; enfim, esta viagem acaba por tornar-se um deslocamento em descobrimento do seu próprio interior, que culmina no grande encontro com a melancolia ao perceber-se um assassino vazio e medíocre.

Com base no estudo realizado, é possível categorizar Uma Viagem à India (2010) como um épico contemporâneo, posto que a narrativa apresenta características marcantes da epopeia clássica, como a divisão de sua estrutura em cantos nos quais apresentam a vida do protagonista, no caso, o antiherói português Bloom, no formato in media res, narrando os grandes ou não tão grandes feitos sobre o itinerário Lisboa, Londres, Paris, Índia. Além disso, é aparente a tentativa de organização da ordem: Proposição, Invocação, Dedicatória, Narração e Epílogo. 
Decorrente dessa estética clássica, Uma Viagem à Índia (2010) se mostra um texto híbrido, uma vez que une essa estrutura à prosa romanesca e aos conflitos típicos do contemporâneo. Gonçalo M. Tavares consegue incorporar aos Cantos do Império de Bloom, os novos dispositivos, dos quais se tratou com base na teoria propostos por Giorgio Agamben (2013), e a rede que se estabelece entre eles ora pelas palavras do protagonista, ora pelo seu pensamento, via discurso do narrador. Além disso, traz a noção, também proposta por Giorgio Agamben (2013), de que a contemporaneidade é a relação com o próprio tempo, uma vez que se pertence ao presente, mas se projeta o pensamento para outros tempos - passado e futuro.

Esse transitar entre diferentes percepções de tempo é que levam Bloom ao sentimento de melancolia que gera as ações dentro da trama. Somando-se a isso, tem-se a teoria de Agamben (2013) sobre as relações interpessoais de amizade refletidas na narrativa de Bloom. Essas relações exibem a confluência de Bloom com aqueles personagens com os quais se depara - Mary, seu pai, os três covardes, Thomas C., Maria E., Jean M., Anish, Shakra, as prostitutas - e o tipo de relações que estabelecem entre si.

Assim posto, o estudo do texto analisado contribui, em realidade, não apenas para categorizar (e identificar 
como tal) a narrativa épica contemporânea, mas, também, para enaltecer a importância de se voltar o olhar, na contemporaneidade, para a produção e leitura de epopeias, bem como - lato sensu - refletir sobre a noção de tempo, de espaço e de sujeito; e as intrincadas e ontogênicas relações humanas de conflito entre o ser e o mundo.

\section{REFERÊNCIAS}

AGAMBEN, Giorgio (2013). O que é o contemporâneo? e outros ensaios. Vinícius Nicastro Honesko. Trad. Chapecó: Argos.

ARISTÓTELES; HORÁCIO; LONGINO (2014). A poética clássica. Jaime Bruna Trad. São Paulo: Cultrix.

BENJAMIN, Walter (1994). "O narrador". In: Magia e técnica, arte e política. 7.ed. São Paulo: Brasiliense, p.197-221.

(1994). "A obra de arte na era de sua reprodutibilidade técnica". In: Magia e técnica, arte e política. 7. ed. São Paulo: Brasiliense, p.166-196. COELHO, Nelly Novaes (1986). Literatura \& linguagem: a obra literária e a expressão linguística. 4.ed. São Paulo: Quíron.

GAGNEBIN, Jeanne-Marie (1993). Do Conceito de mímesis no pensamento de Adorno e Benjamin. Perspectivas, São Paulo, 16, p.67-86. In http:// seer.fclar.unesp.br/perspectivas/article/viewFile/771/632. Acesso em 08.Fev.2014.

LUKÁCS, Georg (2000). A teoria do romance: um ensaio histórico-filosófico sobre as formas da grande épica. Trad. José Marcos Mariani de Macedo. São Paulo: Duas Cidades, p.34.

OLIVEIRA, Rejane Pivetta de (2003). Lukács: Mímese e Implicações de Leitura. In: BORDINI, Maria da Glória Org.. Lukács e a Literatura. Porto Alegre, RS: EDIPUCRS, p.181-208.

PLATÃO (2004). A república. Trad. Enrico Corvisieri. São Paulo: Nova Cultural. 
TAVARES, Gonçalo Manuel (2010). Uma viagem à Índia: melancolia contemporânea (um itinerário). São Paulo: Leya.

WATT, Ian (2010). A ascensão do romance: estudos sobre Defoe, Richardson e Fielding. Trad. Hildergard Feist. São Paulo: Companhia de Bolso.

Isabele Corrêa Vasconcelos Fontes Pereira é Mestre pela URI 2015, Campus de Frederico Westphalen (RS). A agência que fomentou a pesquisa é a CAPES. Atua na Faculdade Antonio Meneguetti, Curso de Bacharelado em Ontopsicologia. Dedica-se a estudar os seguintes temas: Literatura, Literatura Comparada, Literatura Portuguesa e Literaturas Africanas de Língua Portuguesa; Fundamentos Filológicos e Linguísticos. E-mail: isabelecvfp.zizi@gmail.com.

Silvia Helena Niederauer é Doutora pela PUC-RS 2007. Dedica-se a estudar atuando principalmente nos seguintes temas: Teoria da Literatura, Literatura Brasileira, Literatura Portuguesa e Literaturas Africanas de Língua Portuguesa. Leitura e História e Ficção. Atua na URI, Campus Frederico Westphalen (RS).E-mail: silvia.niederauer@yahoo.com.

Ilse Maria da Rosa Vivian é Doutora pela PUC-RS 2014. Dedica-se a estudar atuando principalmente no seguintes temas: Teoria da Literatura, Estudos Culturais, Literatura Portuguesa e Literaturas Africanas de Língua Portuguesa. Atua na URI, Campus Frederico Westphalen (RS). 